\title{
Sex differences in short-and long-term survival among critically ill patients with sepsis: a real-world study using propensity scoring methods
}

Shan Lin

Sun Yat-sen University First Affiliated Hospital

Shanhui Ge

Sun Yat-sen University First Affiliated Hospital

Wanmei He

Sun Yat-sen University First Affiliated Hospital

Lihong Bai

Sun Yat-sen University First Affiliated Hospital

Mian Zeng ( $\nabla$ zengmian@mail.sysu.edu.cn )

Sun Yat-sen University First Affiliated Hospital https://orcid.org/0000-0001-9179-902X

Research

Keywords: critical care, sepsis, sex, prognosis

Posted Date: July 17th, 2020

DOI: https://doi.org/10.21203/rs.3.rs-41722/v1

License: (9) This work is licensed under a Creative Commons Attribution 4.0 International License.

Read Full License 


\section{Abstract \\ Background}

At present, there have been studies showing a correlation between sex differences and prognosis. Nevertheless, the evidence of short- and long-term survival of sex-based differences among critically ill patients with sepsis is still limited and controversial. The purpose of this study was to evaluate the effect of sex on the short- and long-term survival of critically ill patients with sepsis.

\section{Methods}

We used the Medical Information Mart for Intensive Care III database. Cox proportional hazards models were conducted to determine the relationship of 28-day and 1-year mortality rates with a different sex. Interaction and stratified analyses were conducted to test whether the effect of sex differed across various subgroups.

\section{Results}

A total of 12,321 patients were enrolled in this study. After adjustments, the 28-day and 1-year mortality rates for female patients were reduced by $12 \%$ and $10 \%$, respectively $(\mathrm{HR}=0.88,95 \% \mathrm{Cl} 0.81-0.96$ and $\mathrm{HR}=0.90,95 \% \mathrm{Cl} 0.85-0.95)$ when compared to male patients. The effects of the association between sex and 28-day and 1-year mortality were broadly consistent for all subgroup variables. Only a significant interaction of age was observed in 1-year mortality $(P=0.0091)$. Compared with male patients, female patients ( $<50$ years) had better long-term survival advantages (HR $0.7695 \% \mathrm{Cl} 0.62-0.94, P=0.0124)$; on the contrary, for older patients ( $\geq 50$ years), we did not find sex-based differences in long-term survival (HR 1.03, 95\% Cl 0.97-1.09, $P=0.3678$ ).

\section{Conclusions}

In the current retrospective large database review, female patients had a significantly lower 28-day and 1year mortality rates than did males among critically ill patients with sepsis. Of concern, there was an interaction between age and sex, and whether to suggest that female-associated hormones affect clinical outcomes needs to be further researched.

\section{Introduction}

Sepsis, a severe organ dysfunction induced by infection, is one of the leading causes of the intensive care unit (ICU) admissions [1]. It is among the most expensive conditions treated in United States hospitals and a leading cause of death. Sepsis affects more than 19 million people each year [2]. In 2014, about 
174,000 adults in the United States were hospitalized for sepsis, $69.9 \%$ of whom were 60 years or older [3, 4].

Among many factors postulated to affect outcomes in sepsis is the sex of the patients, with a hypothesis that females may have a more excellent immune system activity and lower mortality than in males. In this regard, a variety of experimental and clinical studies have indicated that there are sex-based differences in sepsis. In the septic animal model, the survival rate and immune system response of preestrus female mice were obviously higher than in male mice [5]. Similarly, the survival rate of male mice with sepsis was also increased significantly after androgen receptor blockade [6]. In contrast to animal research, numerous clinical studies revealed that no sex-based difference [7-9], higher mortality risk in males [10,11], or higher mortality risk in females [12-14]. At present, the conclusions of clinical studies on sex differences are controversial. Therefore, determining the association between sex and mortality in sepsis could provide an impetus for exploring its pathophysiological mechanism. If such an association exists, the hormonal status (i.e., androgen and estrogen) of a patient with sepsis should be considered. Also, potential therapies can be obtained from this knowledge. Although there have been many studies on sex and the prognosis of sepsis, this problem is still worth conducting in different populations in order to obtain more convincing evidence. We aimed to determine the effect of sex on clinical outcomes of critically ill patients with sepsis in the Medical Information Mart for Intensive Care III (MIMIC-III) database.

\section{Methods}

\section{Patient data}

We conducted this study in the Medical Information Mart for Intensive Care III (MIMIC-III) database (version: 1.4) [15]. The institutional review boards of Beth Israel Deaconess Medical Center and Massachusetts Institute of Technology Affiliates authorized access to the database (Shan Lin, Record ID: 33460949). Due to the anonymized nature of the data, the informed consent of the patient was not required.

All patients ( $\geq 18$ years) with a diagnosis of sepsis based on a sequential organ failure assessment (SOFA) score $\geq 2$ and suspected infection within the first day of ICU admission were included, and the extraction code for sepsis-3 we used was identified by Johnson et al. [16]. Patients whose follow-up were less than one day were excluded. Only the data from the first ICU admission were analyzed. As previously described, we extracted data using structured query language (SQL) with Navicat Premium [17]. The code and website are publicly available (https://github.com/MIT-LCP/mimic-code) [18].

\section{Outcomes}

The primary outcomes were the 28-day and 1-year mortality rates after ICU admission.

\section{Statistical analysis}


Data were presented as mean \pm standard deviation or median (interquartile range, IQR) for continuous variables and as numbers and percentages for categorical variables. Characteristics of the participants in male and female groups were compared using the Chi-square test for categorical variables and Fisher's exact test or Kruskal-Wallis test for continuous variables. Different Cox regression models were conducted to determine the independent relationships of 28-day and 1-year mortality rates with a different sex. In model I, covariates were adjusted for age, infection site, SOFA, mechanical ventilation on first day, renal replacement therapy on first day, Elixhauser Comorbidity Index (SID30) [19]. In model II, the same as model I, but we replaced SID30 with specific comorbidities, including congestive heart failure, chronic pulmonary disease, valvular disease, peripheral vascular disease, hypertension, diabetes, liver disease, renal failure, AIDS, lymphoma, and tumor. In model III, we used propensity score for adjustment calculated by age, infection site, SOFA, mechanical ventilation on first day, renal replacement therapy on first day, congestive heart failure, chronic pulmonary disease, valvular disease, peripheral vascular disease, hypertension, diabetes, liver disease, renal failure, AIDS, lymphoma, and tumor. The results of the main analysis were used with covariate adjustment using propensity score. Interaction and stratified analyses were conducted to test whether the effect of sex differed across various subgroups classified by age ( $<50$ and $\geq 50)$, SOFA $(<5,5-10,10-15, \geq 15)$, and infection site. EmpowerStats(R)

(www.empowerstats.com, X\&Y solutions, Inc., Boston, MA, USA) and R (http://www.R-project.org, version 3.4.3) were used for data analysis. $P$-values $<0.05$ were considered significant.

\section{Results}

\section{Characteristics of participants}

We included 12,321 patients in this study. As shown in Table 1, the number of males and females was 6,493 and 5,828 , accounting for $52.7 \%$ and $47.3 \%$ respectively; and females were older than males $(68.99 \pm 16.46$ vs. $65.42 \pm 16.20, P<0.001)$. Statistical differences were found between males and females for SID30, infection site, and those who required mechanical ventilation or renal replacement therapy on the first day of ICU admission. The median SOFA scores were the same in the two groups, and the median SID30 score in males was higher than females. In all patients, the most common infection site was bloodstream; and female patients had higher urinary tract infections than males. Male patients who required mechanical ventilation and renal replacement therapy on the first day of ICU admission were significantly higher than females. Hypertension was the most common comorbidity among all patients, accounting for $52.93 \%$. Other detailed results are listed in Table 1.

\section{Clinical outcomes of participants}

In terms of clinical outcomes, the median length of hospital stay and ICU stay in males were more prolonged than in females; the 28-day mortality of male patients was slightly higher than that of female patients (18.57\% vs. $18.14 \%)$, while the 1-year mortality was slightly lower than that of female patients (37.24\% vs. $37.70 \%$ ), but there were no significant differences in 28-day and 1-year mortality between two groups (all $P>0.05$ ) [Table 1]. 


\section{Associations between sex differences and short- and long-term survival}

The multivariable Cox regression analysis showed that the 28-day and1-year mortality of female patients was significantly lower than that of males. In model III, when compared to males, the 28-day and 1-year mortality in females decreased by $12 \%$ and $10 \%$, respectively $(\mathrm{HR}=0.90,95 \% \mathrm{Cl} 0.85-0.95, P=0.0034$ and $\mathrm{HR}=0.90,95 \% \mathrm{Cl} 0.85-0.95, P=0.0003$ ) [Table 2].

In the stratified analysis, the effects of the association between sex and 28-day and 1-year mortality were broadly consistent for all subgroup variables [Table 3 and 4, Figure 1 and 2]. Only age was observed to have significant interactions in 1-year mortality $(P=0.0091)$. Compared with male patients, female patients younger than 50 years of age had better long-term survival advantages $(\mathrm{HR}=0.7695 \% \mathrm{Cl} 0.62$ $0.94, P=0.0124)$; in contrast, for patients with age of $\geq 50$ years, we did not find sex-based differences in short- and long-term survival ( $\mathrm{HR}=1.03,95 \% \mathrm{Cl} 0.97-1.09, P=0.3678)$.

\section{Discussion}

This retrospective cohort study including 12,321 patients compared the association between sex and the 28-day as well as 1 -year mortality. To date, there have been many studies on this issue. However, there is still no consensus, which will be more or less confusing for clinicians. Therefore, it is necessary to carry out such research in different populations, especially in a large database. In our study, female patients had significantly lower 28-day and 1-year mortality than did males among critically ill patients with sepsis; moreover, we further found that an interaction between age and sex, meaning that female patients younger than 50 years of age had a better survival advantage than males, which was unlike in previous studies.

In humans, it had been noted that there are sex-based differences in many diseases, such as hypertension, atherosclerosis, lung disease, and cardiovascular disease [20-25]. Sex differences remained controversial in terms of infection disease and sepsis. A large retrospective study by Martin et al. enrolling 10,422,301 adult sepsis patients indicated that males had higher mortality than females (OR $=1.09,95 \% \mathrm{Cl} 1.05-1.14$ ) [10]. Similarly, a prospective study involving 1692 severe sepsis patients by Adrie et al. revealed that females with severe sepsis had lower hospital mortality than males $(\mathrm{OR}=0.75$, $95 \% \mathrm{Cl} 0.57-0.97)$ [11]. However, such results were only observed in patients over the age of 50 (OR= $0.69,95 \% \mathrm{Cl} 0.52-0.93$ ) [11]. Conversely, the female sex hormone, i.e., estrogen, exhibits an immune activation effect that may contribute to the benefit of females during sepsis [26-28]. In our study, our results were in contrast to Adrie et al. and found that only female patients under the age of 50 years had a better survival than males.

In contrast with our findings and the results above, a prospective, observational, clinical trial conducted by Nachtigall et al. indicated an increase of mortality was related to the female sex in the subgroup analysis with 327 sepsis patients [12]. Eachempati et al. also suggested that female sex was an independent index of increased mortality in critically ill patients [13]. Another large retrospective cohort study including 18,757 severe sepsis/septic shock patients, suggested that females had higher hospital 
mortality than males both in univariate analysis and multivariable regression analysis [14]. Furthermore, there were also some studies that no sex-based difference exists in patients with sepsis [7-9].

Currently, the underlying physiological mechanisms are still not fully understood. There are several possible explanations for sex-based differences. Some evidence-based explanations for this are mainly focused on hormone levels. In the animal models, the survival rate in pre-estrus female mice was obviously higher than that in male mice; and after androgen receptor blockade, the survival rate of male mice was also increased significantly $[5,6]$. A clinical experimental study conducted by Eijk et al. enrolled 15 female and 15 male volunteers measuring sex-specific immune responses to endotoxin revealed that females showed a more pronounced pro-inflammatory innate immune response [29]. May et al. found that estradiol was significantly higher in non-survivors, and serum estradiol was positively associated with mortality in critically ill trauma and surgical patients [30]. Then Angstwurm et al. indicated that a higher level of $17 \beta$-estradiol was associated with a shorter survival rate in patients with severe infections [31]. However, we were unable to determine whether higher estrogen concentrations were associated with lower mortality in females because hormone concentrations were not available in this database.

Notably, to the best of our knowledge, we found for the first time that female patients less than 50 years of age had a better long-term survival advantage than males through interaction and stratified analysis for age $\geq 50$ and $<50$ (the median age of menopause of females in the United States [32]). Although no a statistical difference was observed in the interaction for age and 28-day mortality, a reduction in 28-day mortality was almost certain in females younger than the age of 50 years. Whether this is a crucial clue to a better prognosis caused by estrogen needs to be further verified. Therefore, research on sex-based differences in patients with sepsis is worthy of attention.

The limitations of the study still require to be addressed. Many confounders that could affect the outcomes were considered, and different models were used to adjust potential confounders, but other variables that could not be measured may also affect, especially androgen and estrogen levels. Similarly, no data were available regarding androgen and estrogen levels; we can not determine whether higher estrogen concentrations were associated with lower mortality in females. Other limitations included selection bias, single-center design, and low external validity. However, the strengths of this study were specific study population selected from a sizeable critical care database and different adjustment models, including a propensity score [33].

\section{Conclusions}

Female patients had a significantly lower 28-day and 1-year mortality than did males among critically ill patients with sepsis. Of concern, there was an interaction between age and sex, and whether to suggest that female-associated hormones affect clinical outcomes needs to be further researched.

\section{Perspectives And Significance}


This research focused on exploring the effect of sex on the short- and long-term survival of critically ill patients with sepsis. We found that female patients had a significantly lower 28-day and 1-year mortality rates than did males among critically ill patients with sepsis. Of concern, there was an interaction between age and sex, that is, female patients younger than 50 years of age had a better survival advantage than males. A preliminary rationale for further research on whether female-associated hormones may affect clinical outcomes in critically ill patients with sepsis was established.

\section{Abbreviations}

ICU, intensive care unit; SID30, Elixhauser Comorbidity Index; SOFA, sequential organ failure assessment; AIDS, acquired immune deficiency syndrome; IQR, interquartile range; SQL, structured query language; HR, hazard ratio; OR. odds ratio; $\mathrm{Cl}$, confidence interval.

\section{Declarations}

\section{Acknowledgments:}

Thanks to Ruizhe Wang (Tencent Technology Co., Ltd. Shenzhen, Guangdong, China ) for his help in the SQL code.

\section{Authors' contributions:}

Shan Lin designed the study and wrote the draft of this manuscript, Shan Lin and Shanhui Ge mainly performed data extraction and statistical analysis, Wanmei He and Lihong Bai prepared the tables and figures, Mian Zeng revised this manuscript.

\section{Funding:}

This work was supported by the National Natural Science Foundation of China [Grant number: 81670066]; the Major Science and Technology Planning Project of Guangdong Province, China [Grant number: 2016A020216009]; the Critical Care Research Funding of the Aesculap Academy (2017); the Guangdong Basic and Applied Basic Research Foundation, China [Grant number: 2019A1515011198].

\section{Availability of data and materials:}

The raw data itself is from a third-party dataset available from MIMIC-III, a freely accessible critical care database. Reproduction of their data is not permitted according to the Data Use Agreement of the database but access can be requested here: https://mimic.physionet.org/gettingstarted/access.

\section{Ethics approval and consent to participate:}

The access to the database has been approved by the institutional review boards of Beth Israel Deaconess Medical Center and Massachusetts Institute of Technology Affiliates (Record ID: 33460949). 


\section{Consent for publication:}

Not applicable.

\section{Conflicts of Interest:}

The authors have no conflicts of interest to declare.

\section{References}

1. Singer M, Deutschman CS, Seymour CW, Shankar-Hari M, Annane D, Bauer M, et al. The Third International Consensus Definitions for Sepsis and Septic Shock (Sepsis-3). JAMA. 2016;315(8):801-10.

2. Lagu T, Rothberg MB, Shieh MS, Pekow PS, Steingrub JS, Lindenauer PK. Hospitalizations, costs, and outcomes of severe sepsis in the United States 2003 to 2007. Crit Care Med. 2012;40(3):754-61.

3. Rhee C, Dantes R, Epstein L, Murphy DJ, Seymour CW, Iwashyna TJ, et al. Incidence and trends of sepsis in US hospitals using clinical vs claims data, 2009-2014. JAMA. 2017;318(13):1241-9.

4. Fleischmann C, Scherag A, Adhikari NK, Hartog CS, Tsaganos T, Schlattmann P, et al. International Forum of Acute Care Trialists. Assessment of global incidence and mortality of hospital-treated sepsis: current estimates and limitations. Am J Respir Crit Care Med. 2016;193(3):259-72.

5. Zellweger R, Wichmann MW, Ayala A, Stein S, DeMaso CM, Chaudry IH. Females in proestrus state maintain splenic immune functions and tolerate sepsis better than males. Crit Care Med. 1997;25(1):106-10.

6. Angele MK, Wichmann MW, Ayala A, Cioffi WG, Chaudry IH. Testosterone receptor blockade after hemorrhage in males: restoration of the depressed immune functions and improved survival following subsequent sepsis. Arch Surg. 1997;132(11):1207-14.

7. Angus DC, Linde-Zwirble WT, Lidicker J, Clermont G, Carcillo J, Pinsky MR. Epidemiology of severe sepsis in the United States: Analysis of incidence, outcome, and associated costs of care. Crit Care Med. 2001;29:1303-10.

8. Esper AM, Moss M, Lewis CA, Nisbet R, Mannino DM, Martin GS. The role of infection and comorbidity: Factors that influence disparities in sepsis. Crit Care Med. 2006;34:2576-82.

9. Wichmann MW, Inthorn D, Andress HJ, Schildberg FW. Incidence and mortality of severe sepsis in surgical intensive care patients: the influence of patient gender on disease process and outcome. Intensive Care Med. 2000;26(2):167-72.

10. Martin GS, Mannino DM, Moss M. The effect of age on the development and outcome of adult sepsis. Crit Care Med. 2006;34(1):15-21.

11. Adrie C, Azoulay E, Francais A, Clec'h C, Darques L, Schwebel C, et al. Influence of gender on the outcome of severe sepsis: a reappraisal. Chest. 2007;132(6):1786-93. 
12. Nachtigall I, Tafelski S, Rothbart A, Kaufner L, Schmidt M, Tamarkin A, et al. Gender-related outcome difference is related to course of sepsis on mixed ICUs: a prospective, observational clinical study. Crit Care. 2011;15(3):R151.

13. Eachempati SR, Hydo L, Barie PS. Gender-based differences in outcome in patients with sepsis. Arch Surg. 1999;134(12):1342-47.

14. Pietropaoli AP, Glance LG, Oakes D, Fisher SG. Gender differences in mortality in patients with severe sepsis or septic shock. Gend Med. 2010;7(5):422-37.

15. Johnson AE, Pollard TJ, Shen L, Lehman LW, Feng M, Ghassemi M, et al. MIMIC-III, a freely accessible critical care database. Sci Data. 2016;3:160035.

16. Johnson AEW, Aboab J, Raffa JD, Pollard TJ, Deliberato RO, Celi LA, et al. A comparative analysis of sepsis identification methods in an electronic database. Crit Care Med. 2018;46(4):494.

17. Lin S, Ge S, He W, Zeng M. Association of delayed time in the emergency department with the clinical outcomes for critically ill patients. Q J Med DOI: 10.1093/qjmed/hcaa192.

18. Johnson A, Stone DJ, Celi LA, Pollard TJ. The MIMIC code repository: enabling reproducibility in critical care research. J Am Med Inform Assoc. 2017;25(1):32-9.

19. Steiner C, Elixhauser A, Schnaier J. The healthcare cost and utilization project: an overview. Eff Clin Pract. 2002;5(3):143-51.

20. EUGenMed Cardiovascular Clinical Study Group. Regitz-Zagrosek V, Oertelt-Prigione S, Prescott E, Franconi F, Gerdts E, Foryst-Ludwig A, et al. Gender in cardiovascular diseases: impact on clinical manifestations, management, and outcomes. Eur Heart J 2015;37(1): 24-34.

21. Reckelhoff JF. Gender differences in hypertension. Curr Opin Nephrol Hypertens. 2018;27(3):176-81.

22. Di Giosia P, Giorgini P, Stamerra CA, Petrarca M, Ferri C, Sahebkar A. Gender differences in epidemiology, pathophysiology, and treatment of hypertension. Curr Atheroscler Rep. 2018;20(3):13.

23. Yu J, Mehran R, Grinfeld L, Xu K, Nikolsky E, Brodie BR, et al. Sex-based differences in bleeding and long term adverse events after percutaneous coronary intervention for acute myocardial infarction: Three year results from the HORIZONS-AMI trial. Catheter Cardiovasc Interv. 2015;85(3):359-68.

24. Raghavan D, Jain R. Increasing awareness of sex differences in airway diseases. Respirology. 2016;21(3):449-59.

25. Pinkerton KE, Harbaugh M, Han MK, Jourdan Le Saux C, Van Winkle LS, Martin WJ 2. Women and lung disease. Sex differences and global health disparities. Am J Respir Crit Care Med. 2015;192(1):11-6. nd, et al.

26. Angele MK, Pratschke S, Hubbard WJ, Chaudry IH. Gender differences in sepsis: cardiovascular and immunological aspects. Virulence. 2014;5(1):12-9.

27. Aulock SV, Deininger S, Draing C, Gueinzius K, Dehus O, Hermann C. Gender difference in cytokine secretion on immune stimulation with LPS and LTA. J Interferon Cytokine Res. 2006;26(12):887-92.

28. Frink M, Pape HC, van Griensven M, Krettek C, Chaudry IH, Hildebrand F. Influence of sex and age on mods and cytokines after multiple injuries. Shock. 2007;27(2):151-6. 
29. van Eijk LT, Dorresteijn MJ, Smits P, van der Hoeven JG, Netea MG, Pickkers P. Gender differences in the innate immune response and vascular reactivity following the administration of endotoxin to human volunteers. Crit Care Med. 2007;35(6):1464-9.

30. May AK, Dossett LA, Norris PR, Hansen EN, Dorsett RC, Popovsky KA, et al. Estradiol is associated with mortality in critically ill trauma and surgical patients. Crit Care Med. 2008;36(1):62.

31. Angstwurm MWA, Gaertner R, Schopohl J. Outcome in elderly patients with severe infection is influenced by sex hormones but not gender. Crit Care Med. 2005;33(12):2786-93.

32. Gold EB, Bromberger J, Crawford S, Samuels S, Greendale GA, Harlow SD, et al. Factors associated with age at natural menopause in a multiethnic sample of midlife women. Am J Epidemiol. 2001;153(9):865-74.

33. Kurth T, Walker AM, Glynn RJ, Chan KA, Gaziano JM, Berger K, et al. Results of multivariable logistic regression, propensity matching, propensity adjustment, and propensity-based weighting under conditions of nonuniform effect. Am J Epidemiol. 2006;163(3):262-70.

\section{Tables}

Table 1 Characteristics of participants 


\begin{tabular}{|c|c|c|c|c|}
\hline Variables & All $(\mathrm{N}=12321)$ & Male $(\mathrm{N}=6493)$ & $\begin{array}{l}\text { Female } \\
(\mathrm{N}=5828)\end{array}$ & $\begin{array}{l}P- \\
\text { value }\end{array}$ \\
\hline Age (years) & $67.10 \pm 16.42$ & $65.42 \pm 16.20$ & $68.99 \pm 16.46$ & $<0.001$ \\
\hline SOFA & $5.00(3.00-7.00)$ & $5.00(3.00-7.00)$ & $5.00(3.00-7.00)$ & $<0.001$ \\
\hline $\begin{array}{l}\text { Elixhauser Comorbidity Index } \\
\text { (SID30) }\end{array}$ & $\begin{array}{l}17.00(8.00- \\
26.00)\end{array}$ & $\begin{array}{l}17.00(8.00- \\
26.00)\end{array}$ & $\begin{array}{l}16.00(8.00- \\
25.00)\end{array}$ & 0.005 \\
\hline Infection site & & & & $<0.001$ \\
\hline Bloodstream & $5440(44.15 \%)$ & $2966(45.68 \%)$ & $2474(42.45 \%)$ & \\
\hline Pulmonary & 807 (6.55\%) & $459(7.07 \%)$ & $348(5.97 \%)$ & \\
\hline Abdominal & $265(2.15 \%)$ & $137(2.11 \%)$ & $128(2.20 \%)$ & \\
\hline Urinary tract & $2596(21.07 \%)$ & $1210(18.64 \%)$ & $1386(23.78 \%)$ & \\
\hline Others & $3213(26.08 \%)$ & $1721(26.51 \%)$ & $1492(25.60 \%)$ & \\
\hline $\begin{array}{l}\text { Mechanical ventilation on first } \\
\text { day }\end{array}$ & $6132(49.77 \%)$ & 3357 (51.70\%) & $2775(47.61 \%)$ & $<0.001$ \\
\hline $\begin{array}{l}\text { Renal replacement therapy on } \\
\text { first day }\end{array}$ & $604(4.90 \%)$ & $349(5.38 \%)$ & $255(4.38 \%)$ & 0.010 \\
\hline Length of ICU stay (days) & $3.33(1.83-7.86)$ & $3.55(1.83-8.57)$ & $3.18(1.82-7.14)$ & $<0.001$ \\
\hline Length of hospital stay (days) & $\begin{array}{l}10.85(6.36- \\
19.04)\end{array}$ & $\begin{array}{l}11.68(6.74- \\
20.36)\end{array}$ & $\begin{array}{l}10.04(6.07- \\
17.84)\end{array}$ & $<0.001$ \\
\hline 28-year mortality & $2263(18.37 \%)$ & $1206(18.57 \%)$ & $1057(18.14 \%)$ & 0.531 \\
\hline 1-year mortality & $4615(37.46 \%)$ & $2418(37.24 \%)$ & $2197(37.70 \%)$ & 0.601 \\
\hline \multicolumn{5}{|l|}{ Comorbidities } \\
\hline Congestive heart failure & $4168(33.83 \%)$ & $2226(34.28 \%)$ & $1942(33.32 \%)$ & 0.260 \\
\hline Chronic pulmonary disease & $2716(22.04 \%)$ & $1458(22.45 \%)$ & $1258(21.59 \%)$ & 0.245 \\
\hline Valvular disease & $1747(14.18 \%)$ & $909(14.00 \%)$ & $838(14.38 \%)$ & 0.547 \\
\hline Peripheral vascular disease & $1411(11.45 \%)$ & $720(11.09 \%)$ & $691(11.86 \%)$ & 0.182 \\
\hline Hypertension & $6522(52.93 \%)$ & $3385(52.13 \%)$ & $3137(53.83 \%)$ & 0.060 \\
\hline Diabetes & $3509(28.48 \%)$ & $1817(27.98 \%)$ & $1692(29.03 \%)$ & 0.198 \\
\hline Liver disease & $1258(10.21 \%)$ & $669(10.30 \%)$ & $589(10.11 \%)$ & 0.718 \\
\hline Renal failure & $2226(18.07 \%)$ & $1149(17.70 \%)$ & $1077(18.48 \%)$ & 0.259 \\
\hline AIDS & $180(1.46 \%)$ & $94(1.45 \%)$ & $86(1.48 \%)$ & 0.897 \\
\hline Lymphoma & 309 (2.51\%) & $163(2.51 \%)$ & $146(2.51 \%)$ & 0.985 \\
\hline
\end{tabular}


Data were presented as mean \pm standard deviation or median (interquartile range, IQR) for continuous variables and as numbers and percentages for categorical variables.

Abbreviations: ICU, intensive care unit; SOFA, sequential organ failure assessment; AIDS, acquired immune deficiency syndrome.

Table 2 Cox proportional hazards analysis for sex differences with 28-day and 1-year mortality

\begin{tabular}{|lllll|}
\hline Clinical outcome & & & & \\
\hline 28-day mortality & Sex & HR & $95 \% \mathrm{Cl}$ & -value \\
\hline Crude & Male & 1.0 & - & - \\
\hline Model I & Female & 0.98 & $0.90-1.06$ & 0.6248 \\
\hline Model II & Male & 1.0 & - & - \\
& Female & 0.97 & $0.89-1.05$ & 0.4093 \\
\hline Model III & Male & 1.0 & - & - \\
\hline 1-year mortality & Sexale & 0.94 & $0.86-1.02$ & 0.1380 \\
\hline Crude & Male & 1.0 & - & - \\
& Female & 0.88 & $0.81-0.96$ & 0.0034 \\
\hline Model I & Male & 1.0 & - & - \\
& Female & 1.01 & $0.96-1.07$ & 0.6413 \\
\hline Model II & Male & 1.0 & - & - \\
& Female & 0.95 & $0.90-1.01$ & 0.1155 \\
\hline Model III & Male & 1.0 & - & - \\
\hline & Female & 0.93 & $0.88-0.99$ & 0.0193 \\
\hline & Male & 1.0 & - & - \\
\hline & Female & 0.90 & $0.85-0.95$ & 0.0003 \\
\hline
\end{tabular}

Abbreviations: $\mathrm{HR}$, hazard ratio; $\mathrm{Cl}$, confidence interval. 
Model I adjust for: age (years), infection site, SOFA, mechanical ventilation on first day, renal replacement therapy on first day, Elixhauser Comorbidity Index (SID30).

Model II adjust for: age (years), infection site, SOFA, mechanical ventilation on first day, renal replacement therapy on first day, congestive heart failure, chronic pulmonary disease, valvular disease, peripheral vascular disease, hypertension, diabetes, liver disease, renal failure, AIDS, lymphoma, tumor.

Model III was adjusted by propensity score calculated by age (years), infection site, SOFA, mechanical ventilation on first day, renal replacement therapy on first day, congestive heart failure, chronic pulmonary disease, valvular disease, peripheral vascular disease, hypertension, diabetes, liver disease, renal failure, AIDS, lymphoma, tumor.

Table 3 Effect size of sex difference in 28-day mortality rate in prespecified and exploratory subgroups in each subgroup

\begin{tabular}{|lllll|}
\hline & Male & Female $(\mathrm{HR}, 95 \% \mathrm{Cl})$ & $P$-value & $P$ interaction \\
\hline Age & & & & 0.0535 \\
\hline$<50$ & 1.0 & $0.77(0.56-1.04)$ & 0.0894 & \\
\hline SOFA & 1.0 & $1.04(0.95-1.13)$ & 0.3898 & \\
\hline$<5$ & & & & 0.1542 \\
\hline$\geq 5,<10$ & 1.0 & $0.91(0.80-1.03)$ & 0.1219 & \\
\hline$\geq 10,<15$ & 1.0 & $1.10(0.90-1.35)$ & 0.3379 & \\
\hline$\geq 15$ & 1.0 & $0.81(0.47-1.37)$ & 0.4221 & \\
\hline Infection site & & & & 0.4524 \\
\hline Bloodstream & 1.0 & $0.90(0.79-1.02)$ & 0.0887 & \\
\hline Pulmonary & 1.0 & $0.80(0.58-1.11)$ & 0.1859 & \\
\hline Abdominal & 1.0 & $0.91(0.56-1.47)$ & 0.6945 & \\
\hline Urinary tract & 1.0 & $0.94(0.79-1.12)$ & 0.5046 & \\
\hline Others & 1.0 & $1.08(0.90-1.29)$ & 0.4046 & \\
\hline
\end{tabular}

Abbreviations: $\mathrm{HR}$, hazard ratio; $\mathrm{Cl}$, confidence interval.

Note: Adjust for age (years), infection site, SOFA, mechanical ventilation on first day, renal replacement therapy on first day, congestive heart failure, chronic pulmonary disease, valvular disease, peripheral 
vascular disease, hypertension, diabetes, liver disease, renal failure, AIDS, lymphoma, and tumor except for the subgroup variable.

Table 4 Effect size of sex difference in 1-year mortality rate in prespecified and exploratory subgroups in each subgroup

\begin{tabular}{|lllll|}
\hline & Male & Female $(\mathrm{HR}, 95 \% \mathrm{Cl})$ & $P$-value & $P$ interaction \\
\hline Age & & & & 0.0091 \\
\hline$<50$ & 1.0 & $0.76(0.62-0.94)$ & 0.0124 & \\
\hline $\mathbf{2} 50$ & 1.0 & $1.03(0.97-1.09)$ & 0.3678 & \\
\hline SOFA & & & & 0.3596 \\
\hline$<5$ & 1.0 & $0.93(0.85-1.02)$ & 0.1012 & \\
\hline$\geq 5,<10$ & 1.0 & $0.92(0.84-1.00)$ & 0.0612 & \\
\hline$\geq 10,<15$ & 1.0 & $0.99(0.83-1.18)$ & 0.9258 & \\
\hline$\geq 15$ & 1.0 & $0.80(0.50-1.29)$ & 0.3612 & \\
\hline Infection site & & & & 0.0938 \\
\hline Bloodstream & 1.0 & $0.90(0.83-0.99)$ & 0.0263 & \\
\hline Pulmonary & 1.0 & $0.85(0.68-1.07)$ & 0.1729 & \\
\hline Abdominal & 1.0 & $0.82(0.56-1.20)$ & 0.3170 & \\
\hline Urinary tract & 1.0 & $0.89(0.79-1.01)$ & 0.0613 & \\
\hline Others & 1.0 & $1.07(0.95-1.21)$ & 0.2657 & \\
\hline
\end{tabular}

Abbreviations: $\mathrm{HR}$, hazard ratio; $\mathrm{Cl}$, confidence interval.

Note: Adjust for age (years), infection site, SOFA, mechanical ventilation on first day, renal replacement therapy on first day, congestive heart failure, chronic pulmonary disease, valvular disease, peripheral vascular disease, hypertension, diabetes, liver disease, renal failure, AIDS, lymphoma, and tumor except for the subgroup variable.

\section{Figures}




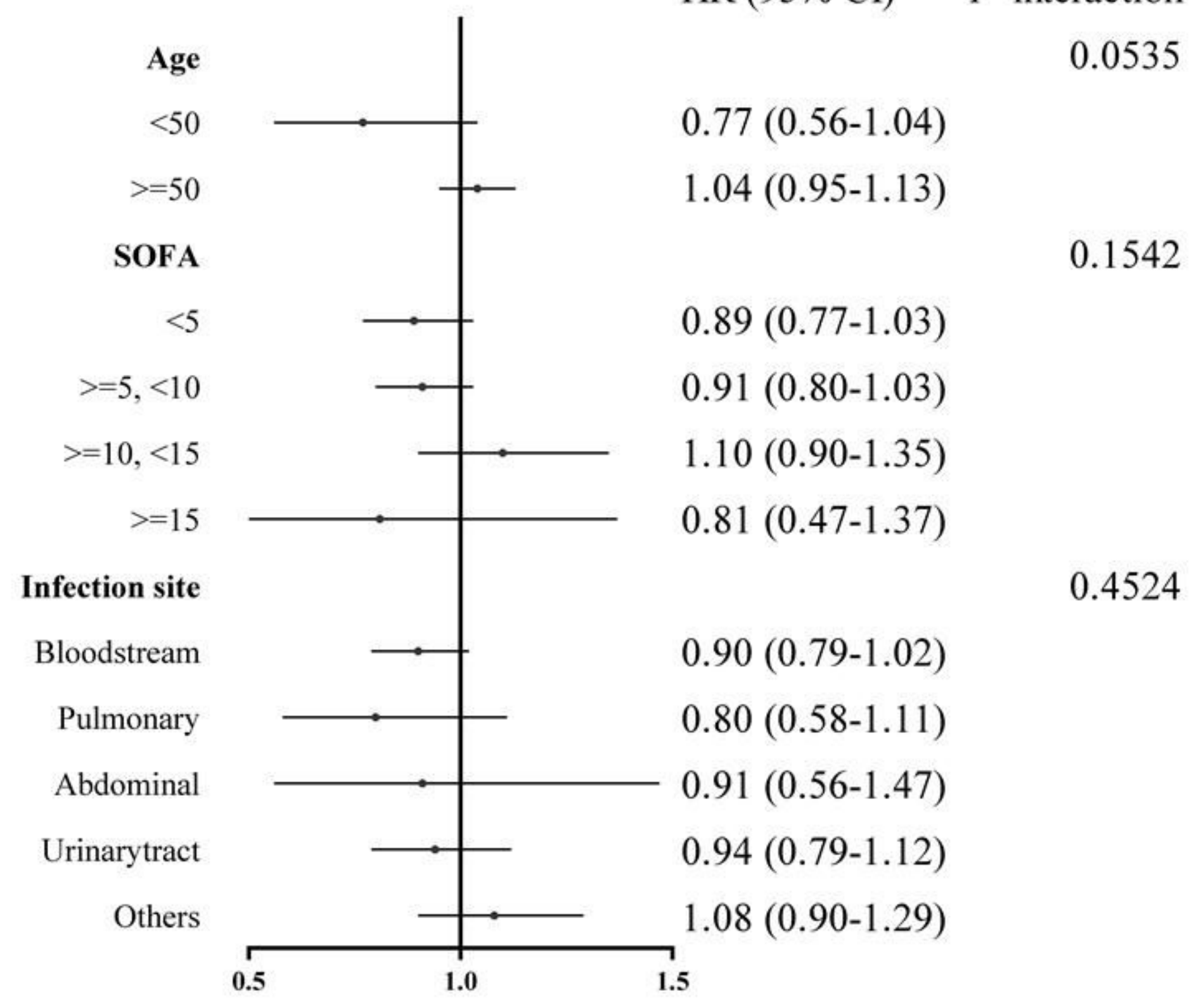

Figure 1

Forest plot of sex difference on 28-day mortality rate in prespecified and exploratory subgroups in each subgroup 


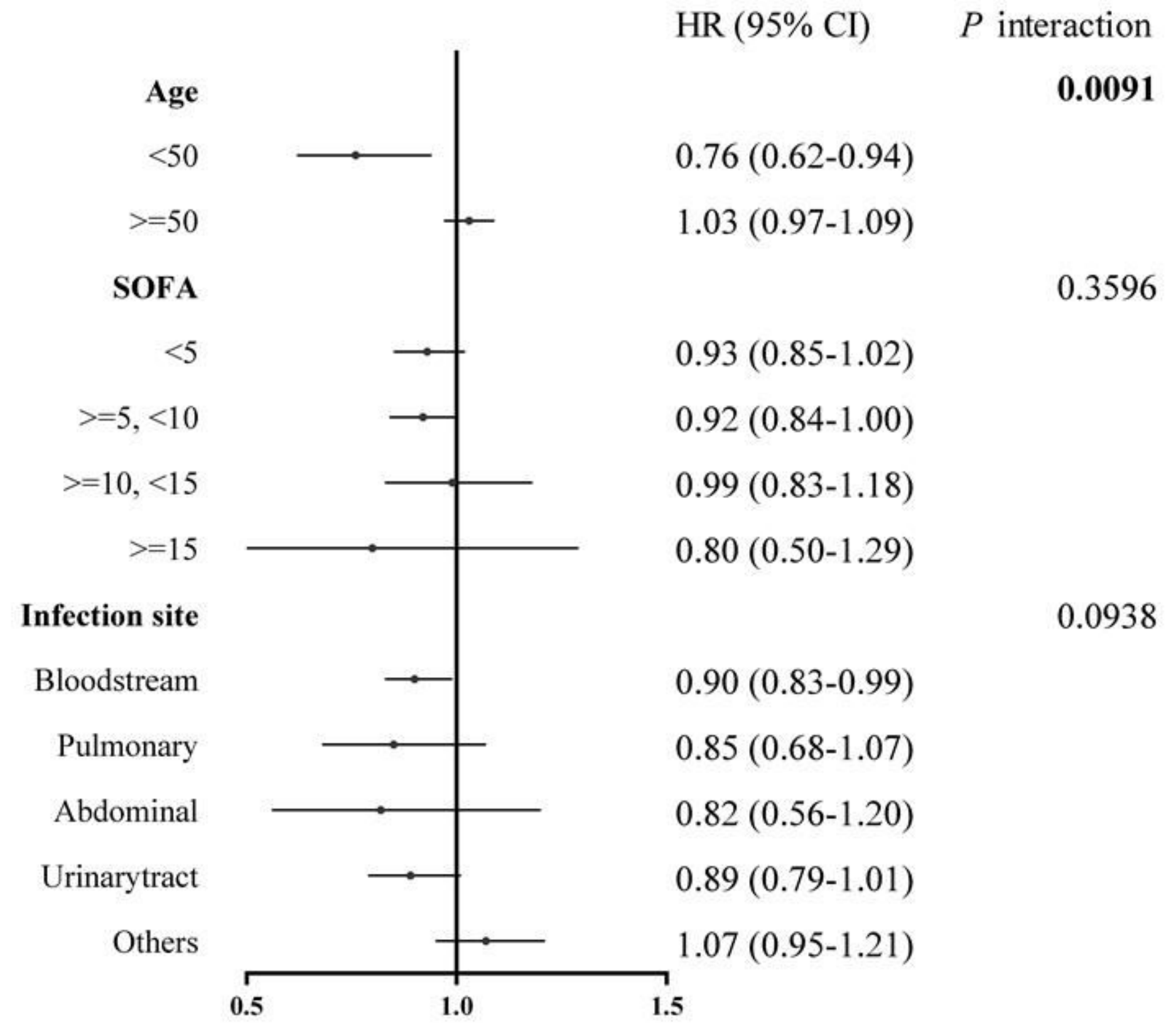

Figure 2

Forest plot of sex difference on 1-year mortality rate in prespecified and exploratory subgroups in each subgroup 